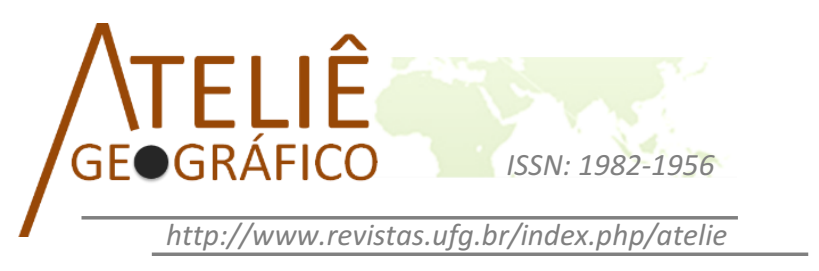

\title{
Desigualdades intraurbanas e condicionantes socioambientais: elementos para a delimitação de zonas de risco a ocorrência da Leptospirose
}

\author{
Intra-urban inequalities and socio-environmental \\ conditions: elements for the delimitation of Leptospirosis \\ risk areas \\ Desigualdades intraurbanas y las condiciones \\ socioambientales: elementos para la definición de zonas de \\ riesgo de la aparición de la Leptospirosis
}

\author{
Márcia Eliane Silva Carvalho \\ Universidade Federal de Sergipe \\ marciacarvalho_ufs@yahoo.com.br \\ Francisco de Assis Mendonça \\ Universidade Federal do Paraná \\ chico@ufpr.br
}

\begin{abstract}
Resumo
Este artigo tem como objetivo identificar zonas de risco para a leptospirose no ambiente urbano em Aracaju/SE/BR, buscando identificar o perfil da doença no recorte espacial em estudo, bem como o contexto no qual a doença se expressa e suas relações com as variáveis socioambientais no recorte temporal de 2010 a 2015. Trata-se de um estudo ecológico, descritivo, analítico e quantitativo, com uso da pesquisa bibliográfica e documental a partir de dados secundários, finalizando com o recurso da modelagem geoespacial. $\mathrm{O}$ modelo elaborado para o risco à leptospirose em Aracaju delimitou três zonas distintas na qual a de mais alto risco abrange os bairros da periferia norte da cidade, bem como a zona periférica sul, ambas com os mais baixos níveis de renda e deficiências na infraestrutura local. $O$ reconhecimento de áreas de risco do ponto de vista socioambiental com concentração da doença torna-se importante para as ações de controle de endemias desde que integradas a outras políticas públicas voltadas para melhoria no saneamento, habitação, educação e distribuição de renda.
\end{abstract}

Palavras chave: Ambiente Urbano, Saúde coletiva, Risco socioambiental, Leptospirose 


\begin{abstract}
This paper aims to identify Leptospirosis risk areas in the urban environment in Aracaju, capital city of the State of Sergipe in Brazil, seeking to identify the profile of the disease in the area studied, as well as the context in which the disease happens and its relations with socio-environmental variables, from 2010 to 2015. This is an ecological, descriptive, analytical and quantitative study, using bibliographical and documentary research based on secondary data, ending with the use of geospatial modeling. The model which was prepared for the Leptospirosis risk in Aracaju delimited three distinct zones, in which the one of highest risk covers the neighborhoods of the northern periphery of the city, as well as the southern peripheral zone, both with the lowest levels of income and deficiencies in terms of infrastructure. The acknowledge of socio-environmental risk areas with disease concentration becomes important for endemic control actions, since they are integrated with other public policies aimed at improving sanitation, housing, education and income distribution.
\end{abstract}

Keywords: Urban Environment, Collective health, Socio-environmental risk, Leptospirosis.

\begin{abstract}
Resumen
Este artículo tiene como objetivo identificar las zonas de riesgo para la leptospirosis en el entorno urbano en Aracaju / SE / BR, buscando identificar el perfil de la enfermedad en el área espacial en estudio, así como el contexto en el que se expresa la enfermedad y sus relaciones con las variables socioambientales en el marco de tiempo 2010-2015. Se trata de un estudio ecológico, descriptivo, analítico y cuantitativo, mediante la investigación bibliográfica y documental de los datos secundarios, terminando con el uso de la modelización geoespacial. El modelo preparado para el riesgo de leptospirosis en Aracaju delineó tres áreas distintas en las que el mayor riesgo abarca los barrios de la periferia norte de la ciudad, así como la zona periférica del sur, todas con los más bajos niveles de renta y deficiencias en la infraestructura local. El reconocimiento de las zonas de riesgo en el punto de vista socioambiental con la concentración de la enfermedad se hace importante para el control de enfermedades endémicas desde que integradas en otras políticas públicas destinadas a mejorar el saneamiento, la vivienda, la educación y la distribución de renta.
\end{abstract}

Palabras clave: Ambiente urbano, Salud pública, Riesgo socioambiental, Leptospirosis.

\title{
Introdução
}

As desigualdades intraurbanas na maioria das cidades brasileiras refletem a apropriação desigual dos espaços citadinos associadas ao valor econômico embutido aos mesmos. Consequentemente, recortes espaciais dotados de melhor infraestrutura abrigam pequena parcela da população de mais alta renda, enquanto que nos espaços mais periféricos da cidade, carente de toda uma série de elementos estruturantes, sobrevive a população mais pauperizada. 
Este é o reflexo do processo de urbanização acelerado vivenciado nas últimas décadas, com elevada concentração de capital e ausência de políticas públicas que atendam aos interesses da maioria dos citadinos. Para Carlos (2007, p. 15),

\begin{abstract}
...a "gestão" ao privilegiar determinadas áreas da cidade - abrindo avenidas, destruindo bairros, fechando ruas, impedindo usos e determinando outros - implode a sociabilidade, desloca os habitantes, influencia a valorização/desvalorização dos bairros da cidade e acentua a desigualdade.
\end{abstract}

Neste viés, Mendonça (2011) amplia a análise associando esta realidade aos riscos socioambientais em meio urbano. De acordo com o autor,

\begin{abstract}
...os riscos socioambientais urbanos dizem respeito aos fenômenos imbricados de contingências naturais e sociais que desestabilizam as condições de vida das sociedades urbanas; eles evidenciam elementos e fatores de ordem natural (ambiental) e social (cultural, política, econômica e tecnológica).
\end{abstract}

Neste mesmo contexto, os recursos hídricos que compõem a paisagem geográfica de muitas cidades (e que outrora foram fonte de sua gênese) têm sido cada vez mais pressionados e degradados, sendo potencial fonte de risco para a sociedade em função da deterioração da qualidade de suas águas.

O tratamento adequado das águas urbanas, definida por Tucci (2008, p. 100) como "o sistema de abastecimento de água e esgotos sanitários, a drenagem urbana e as inundações ribeirinhas e a gestão dos sólidos totais", muitas vezes contempla apenas a cidade formal, seu centro e bairros de classe alta, enquanto que nas zonas periféricas predominam ainda ausência de saneamento, ampliando os riscos de contágio de doenças infecto-contagiosas em populações vulneráveis do ponto de vista social e ambiental.

Dentre estas doenças destacam-se as de veiculação hídrica como a febre amarela, malária, dengue, esquistossomose, amebíase, cólera, micoses, leptospirose, cuja morbidade ainda é considerada alta no Brasil, acometendo em muitos casos, a população mais vulnerável do ponto de vista socioeconômico (CONFALONIERI, 2003; MENDONÇA, 2005; BARCELLOS, 2009).

Dentre estas, destaca-se nesta pesquisa a leptospirose, enfermidade causada por uma bactéria espiroqueta patogênica do gênero Leptospira, uma zoonose de elevada abrangência no mundo, presente na urina de roedores e transmitida aos humanos, principalmente nas enchentes.

Dentre os sintomas, destaca-se a febre alta e dores, podendo evoluir para a icterícia, problemas urinários, tosse e sangramentos, causando letalidade em até $40 \%$ dos casos mais graves. É considerada como um agravo de notificação compulsória, sendo o homem considerado um hospedeiro acidental e terminal dentro da cadeia de transmissão, sendo pouco eficiente na transmissão da doença. 
De acordo com dados do Ministério da Saúde (SINAN/SVS), foram notificados, entre os anos de 2010 a 2015, 25.139 casos de leptospirose no país, concentrados principalmente na região Sudeste, Sul e Norte (33\%, 30\% e 21\%, respectivamente). Para a Região Nordeste, no mesmo período, foram registrados 3.527 casos, o que representa $14 \%$ do total nacional. Em Sergipe, para o mesmo período, foram registrados 268 casos, representando 7,6\% do total de casos de sua região, sendo que na capital, Aracaju, apresentou 40,7\% dos casos em relação ao Estado, com 106 casos registrados no recorte temporal em estudo.

Estes dados refletem o contexto social complexo associado a leptospirose, cujas variáveis socioambientais necessitam ser consideradas em conjunto para entender a espacialização e a incidência da leptospirose nos centros urbanos.

Diante deste contexto e considerando que a leptospirose é uma doença que figura como um problema de saúde pública no contexto urbano brasileiro (BARCELLOS e SABROZA, 2001; MAGALHÃES, et.al., 2009; OLIVEIRA, 2009; BUFFON e MENDONÇA, 2014; PEREIRA, 2014) toma-se como recorte de análise o município de Aracaju/SE/BR, cujas pesquisas sobre a leptospirose necessitam ser atualizadas e ampliadas.

Assim, este artigo tem como objetivo identificar zonas de risco para a leptospirose no ambiente urbano em Aracaju/SE/BR, utilizando o software Surfer v.13, buscando identificar o perfil da doença no recorte espacial em estudo, sua incidência e frequência, bem como o contexto no qual a doença se expressa e suas relações com as variáveis socioambientais. Para tal, foi tomando como recorte temporal os casos notificados durante os anos de 2010 a 2015.

\section{Encaminhamentos Metodológicos}

Para atingir os objetivos propostos, a referida pesquisa recebeu aprovação do Comitê de Ética em Pesquisa com Seres Humanos da Universidade Federal de Sergipe através da Plataforma Brasil, número CAAE 58211916.0.0000.5546, de acordo com a Resolução $n^{\circ}$ 466, de 12 de dezembro de 2012, do Conselho Nacional de Saúde, bem como aprovação pelo Centro de Educação Permanente em Saúde de Aracaju (CEPS/SMS), conforme normas da Secretaria Municipal de Saúde de Aracaju.

Esta pesquisa está alicerçada em dois campos do conhecimento: Geografia da Saúde e Epidemiologia. Ambas contribuíram para o entendimento da multicausalidade da ocorrência das doenças no contexto socioambiental, tendo esta pesquisa sido definida como um estudo ecológico, descritivo, analítico e quantitativo, com uso da pesquisa bibliográfica e documental a partir de dados secundários, sem realizar experimentos diretos com seres humanos.

Desta forma, para analisar o perfil de leptospirose em Aracaju foi utilizado o banco de dados de notificação da leptospirose da Coordenação de Vigilância Epidemiológica da Secretaria Municipal de Saúde de Aracaju/SE (SMS). O referido banco é alimentado pelo roteiro de notificação epidemiológica obrigatório para 
leptospirose. Neste banco encontram-se disponíveis informações sobre o número total de casos, a data de ocorrência dos primeiros sintomas, data de notificação, sexo do indivíduo, escolaridade, ambiente provável da infecção, localização residencial, dentre outros dados. A série temporal escolhida ocorreu em função da disponibilidade de dados.

Buscando identificar não apenas os totais absolutos de ocorrência, foi determinada também a incidência de ocorrência da leptospirose por bairros de Aracaju. Para o cálculo da taxa de incidência (I) foi utilizada a seguinte fórmula:

$\mathrm{I}=$ número de casos novos $\mathrm{x} 10^{\mathrm{n}} /$ população por bairro, onde $n$ equivale ao tamanho da amostra da população. Foi considerado $n=5$, para expressar o resultado por 100.000 habitantes.

Para geração do banco de dados e posterior construção de tabelas e gráficos foi utilizado o Excel/Windows/07. Para elaboração dos mapas foi utilizada base de dados da Superintendência de Recursos Hídricos de Sergipe - SRH (2014) e da Prefeitura Municipal de Aracaju - PMA (2010) e o ArcGis 10.1 como software, buscando identificar padrões espaciais de localização das áreas de risco nas quais ocorreu a maior incidência das morbidades.

O processamento estatístico foi descritivo e probabilístico, usando-se o Coeficiente de Correlação de Pearson para avaliar a correlação entre o componente climático e o aumento dos casos de leptospirose. Para tal, os dados de precipitação foram considerados como a variável independente e os casos de leptospirose como variáveis dependentes. Para análise dos resultados foi considera classificação de Dancey e Reidy (2006): 0 a 0.30 indica fraca correlação; 0.40 a 0.6 (positivo ou negativo) indica correlação moderada; 0.70 a 1 (positiva ou negativa) indica forte correlação.

Para a delimitação de zonas de risco (ZR) para a leptospirose utilizou-se o recurso da modelagem geoespacial utilizando o software Surfer v. 13, a partir da adaptação da proposta de Melo (2016). Foi realizado o georreferenciamento dos casos notificados de leptospirose. Foram tomados como parâmetros de análise para compor o banco de dados a renda (R), a rede de esgoto (RE), o tipo de pavimentação (TP) e a ocorrência de alagamentos (A), sendo estes considerados pela literatura especializada sobre a leptospirose como condicionantes socioambientais que determinam um maior ou menor grau de risco à população. As duas primeiras variáveis tiveram como fonte os dados do IBGE (2010), o tipo de pavimentação foi determinado a partir das pesquisas de campo e a ocorrência dos alagamentos baseou-se na pesquisa desenvolvida por Brazil (2016).

Vale ressaltar que os dados sobre coleta de lixo não foram utilizados no modelo devido a inconsistência dos dados, buscando evitar, desta forma, possíveis incoerências ao modelo proposto.

Para cada um dos parâmetros definidos foi dado um valor entre 1 e 10 no qual um significa a melhor situação e dez caracteriza a situação mais degradante da variável em análise, resultando na identificação de um valor final denominado PP (peso por 
ponto) para cada caso notificado de leptospirose no período em estudo, conforme fórmula abaixo:

$$
\mathrm{PP}=\frac{\mathrm{R}+\mathrm{RE}+\mathrm{TP}+\mathrm{A}}{4}
$$

Foi utilizada a krigagem, devido suas características possibilísticas, sendo os valores introduzidos no banco de dados e extrapolados possibilitando simular ambientes e identificando a relação entre a ocorrência da leptospirose com as desigualdades urbanas em Aracaju e seus respectivos condicionantes socioambientais em análise (MELO, 2016).

O resultado da modelagem foi apresentado em três classes, a partir da integração das variáveis em análise, associadas às Zonas de Risco à leptospirose. Os valores até 3 foram considerados como a Zona de Baixo Risco; de 3,1 a 6 Zona de Risco Médio e acima de 6 foi considerado Zona de Elevado Risco a leptospirose.

Assim, os dados foram analisados de forma integrada buscando compreender as relações entre as variáveis, associada com a literatura pertinente à temática, relacionando os casos de leptospirose as condições socioambientais do espaço urbano de Aracaju.

\section{Área de Estudo}

Localizada na região litorânea do Nordeste Brasileiro, Aracaju apresenta uma área total de $181,8 \mathrm{~km}^{2}$ (Figura 01). Encontra-se dividida entre duas bacias hidrográficas: Sergipe e Vaza Barris. Ao Norte, limita-se com o rio do Sal e ao Sul com o rio VazaBarris; a Oeste, com os municípios de Nossa Senhora do Socorro e São Cristóvão, e a Leste com o Rio Sergipe e o Oceano Atlântico. A população total estimada para 2016 é de 641.523 habitantes, dividida desigualmente entre 40 bairros. A densidade demográfica de $3.528,7 \mathrm{hab} / \mathrm{km}^{2}$, apresentando o mais alto IDH do estado $(0,770)$, embora não socialmente bem distribuído, com índice de pobreza de 27,45\% (IBGE, 2010). 


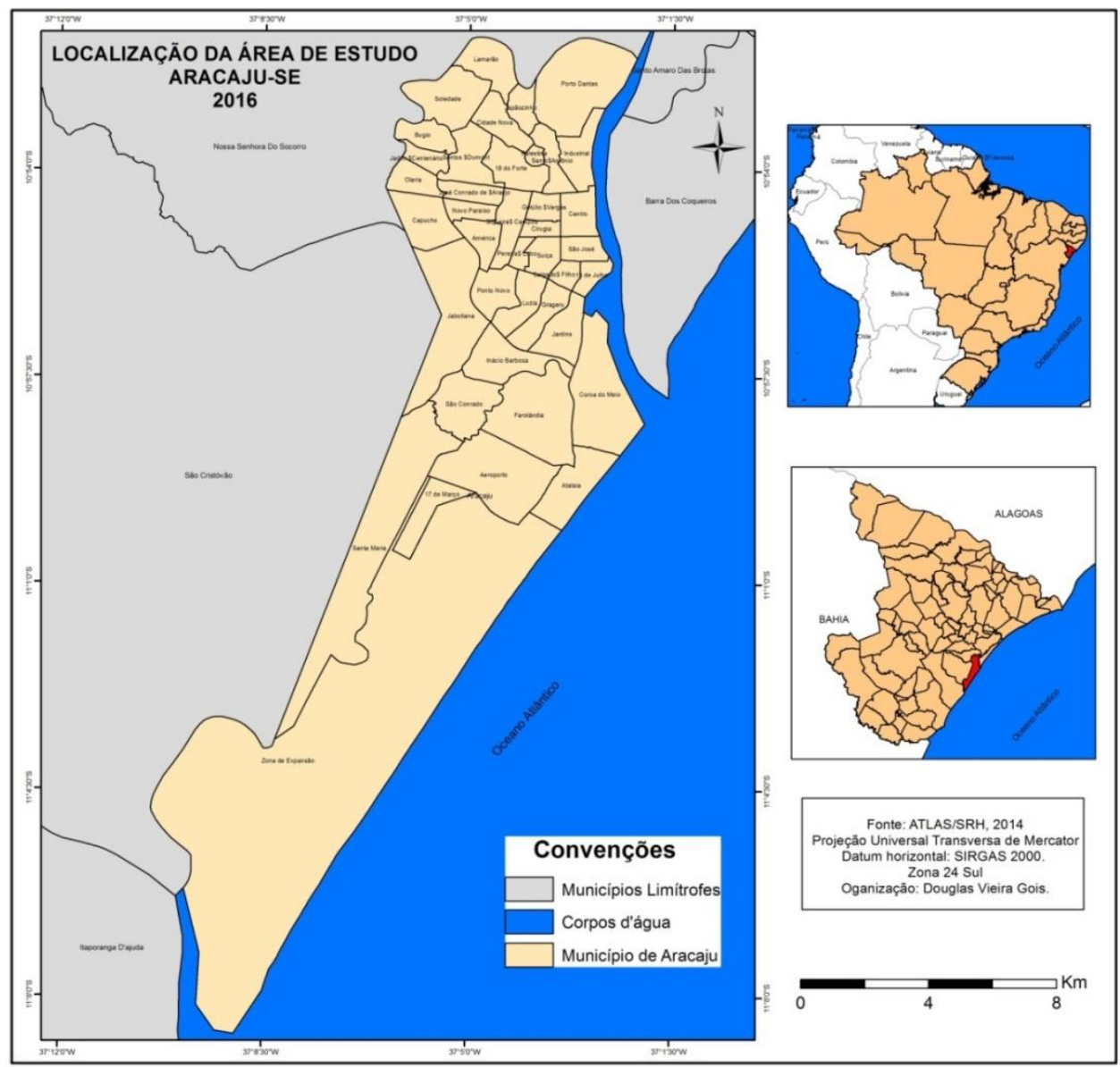

Figura 01. Área de estudo.

Fonte: ATLAS/SRH, 2014.

Org.: GOIS, D. V.

Aracaju é considerada como totalmente urbanizada, tendo apresentado nas últimas décadas um rápido crescimento populacional, com aumento da ocupação de áreas periféricas e expansão habitacional sobre os municípios vizinhos o que trouxe como consequências a formação de assentamentos subnormais na periferia da cidade e degradação socioambiental em função da ocupação em áreas de preservação permanente sem adequada infraestrutura para a população em termos de saneamento.

O maior bairro de Aracaju é o Farolândia 38.257 habitantes. Em segundo lugar situa-se o bairro Santa Maria 33.475 habitantes, seguido pelo São Conrado, com 30.675, Zona de Expansão, com 27.899 e em quinta posição o bairro Santos Dumont com 25.808 habitantes (Tabela 01). Vale destacar que destes, o Santa Maria, São Conrado e Santos 
Dumont são caracterizados como um dos que apresentam menor renda por responsável por domicilio de toda a cidade.

Tabela 01. Zonas e Bairros de Aracaju (2016).

\begin{tabular}{|c|c|c|c|c|c|}
\hline Zona & Bairro & População & Zona & Bairro & População \\
\hline \multirow{15}{*}{ Norte } & Lamarão & 8.983 & \multirow{18}{*}{ Sul } & Farolândia & 38.257 \\
\hline & Soledade & 9.484 & & Luzia & 20.430 \\
\hline & Porto Dantas & 10.858 & & Coroa de Meio & 18.871 \\
\hline & Japãozinho & 8.366 & & Grageru & 17.413 \\
\hline & Cidade Nova & 21.220 & & Inácio Barbosa & 13.887 \\
\hline & Bugio & 17.773 & & Atalaia & 11.799 \\
\hline & $\begin{array}{l}\text { Jardim } \\
\text { Centenário }\end{array}$ & 14.214 & & Suíça & 11.051 \\
\hline & Santos Dumont & 25.808 & & Aeroporto & 10.571 \\
\hline & 18 de Forte & 22.251 & & 13 de Julho & 8.328 \\
\hline & Palestina & 4.340 & & Jardins & 7.126 \\
\hline & Santo Antônio & 12.459 & & Pereira Lobo & 5.942 \\
\hline & Industrial & 18.007 & & São José & 5.587 \\
\hline & Total & 173.763 & & Salgado Filho & 3.992 \\
\hline & & & & São Conrado & 30.675 \\
\hline & & & & Zona de Expansão & 27.899 \\
\hline \multirow{9}{*}{ Oeste } & Olaria & 17.188 & & Santa Maria & 33.475 \\
\hline & Capucho & 956 & & 17 de Março & sem dados \\
\hline & Jabotiana & 17.157 & & Total & 265.303 \\
\hline & Ponto Novo & 22.762 & \multirow{6}{*}{ Centro } & & \\
\hline & América & 15.870 & & Getúlio Vargas & 6.587 \\
\hline & $\begin{array}{l}\text { José Conrado de } \\
\text { Araújo }\end{array}$ & 12.983 & & Cirurgia & 5.349 \\
\hline & Novo Paraíso & 11.134 & & Centro & 7.572 \\
\hline & Siqueira Campos & 14.525 & & Total & 19.508 \\
\hline & Total & 112.575 & & & \\
\hline
\end{tabular}

Fonte: IBGE (2010).

\section{Perfil da Leptospirose em Aracaju}

Entre os anos de 2001 a 2015 foram notificados 302 de casos de leptospirose em Aracaju (Figura 02). Valores superiores à média ao longo deste período foram registrado nos anos de 2001, 2007, 2008, 2010 e 2011.

Nestes anos, a precipitação foi elevada apresentando correlação positiva alta (Pearson de 0,723) com o aumento do número de casos de leptospirose. Em 2008, 2010 e 2011 ocorreu o maior número de eventos extremos de precipitação, fator importante a ser considerado, que concomitante com um sistema de saneamento deficiente, precárias 
habitações e ambiente vulnerável forma um cenário de risco diferenciado para a população dos centros urbanos, a exemplo das pesquisas desenvolvidas por Magalhães, et.al. (2009) e Buffon e Mendonça (2014).

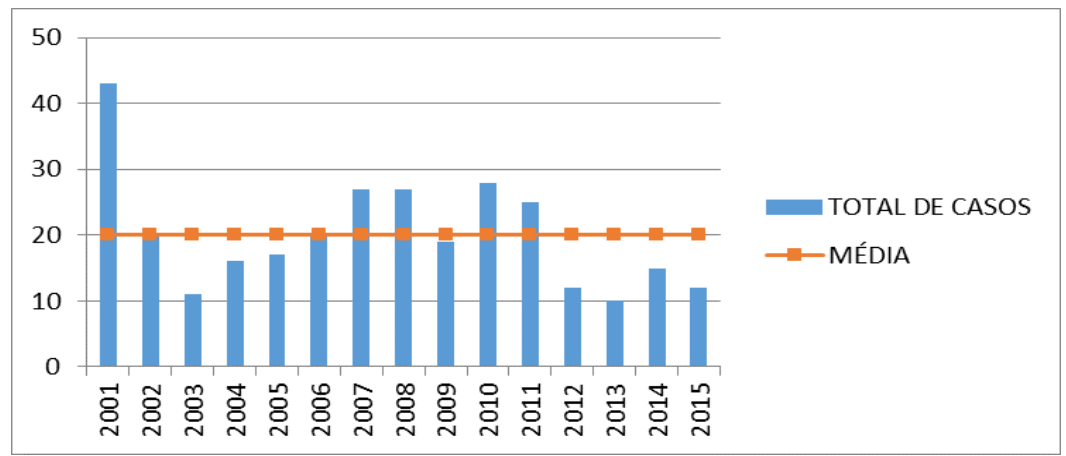

Figura 02. Casos registrados de leptospirose em Aracaju/SE/BR (2001-2015) Fonte: DATASUS (2001-2010); Secretaria Municipal de Saúde de Aracaju/SE (2010-2015); Org.: CARVALHO, M. E. S; MENDONÇA, F. A.

De acordo com os dados da Vigilância Epidemiológica de Aracaju, entre os anos de 2010 a 2015 , vinte cinco pessoas vieram a óbito em função da leptospirose, o que totaliza $23,5 \%$ do total para o período, valor considerado elevado para um país em desenvolvimento (Figura 03).

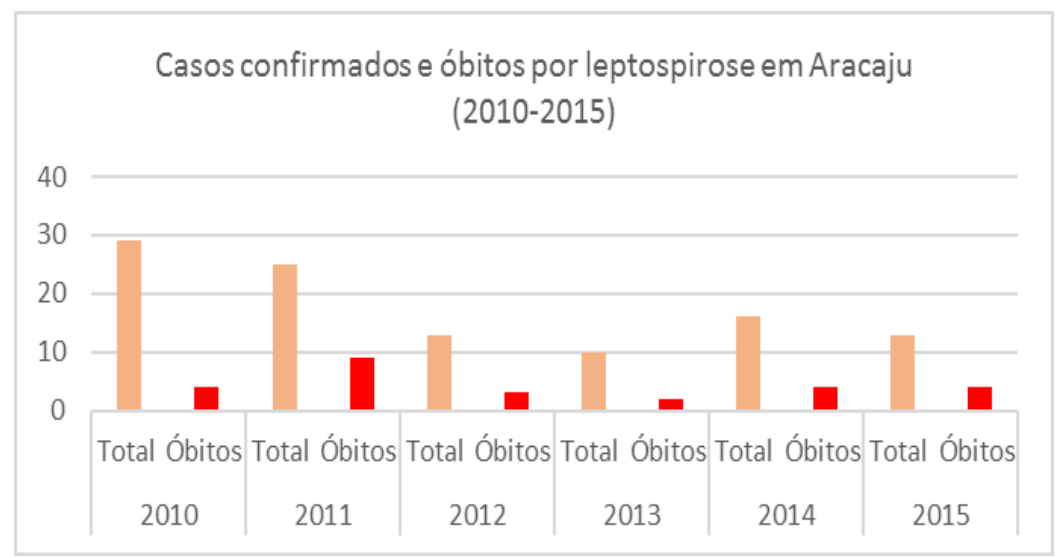

Figura 03. Casos registrados e óbitos por leptospirose em Aracaju/SE/BR.

Fonte: Secretaria Municipal de Saúde de Aracaju/SE (2016). Org.: CARVALHO, M. E. S; MENDONÇA, F. A.

No recorte temporal em estudo, a análise da data dos primeiros sintomas foi utilizada como base para avaliar a correlação da doença com a precipitação. A partir desta análise, foi identificado que $81 \%$ dos casos de leptospirose ocorreram na quadra 
chuvosa, em todos os anos em estudo, que ocorre de abril a agosto, sendo que em setembro ainda ocorrem reflexos da ocorrência das chuvas no ambiente (Figura 04).

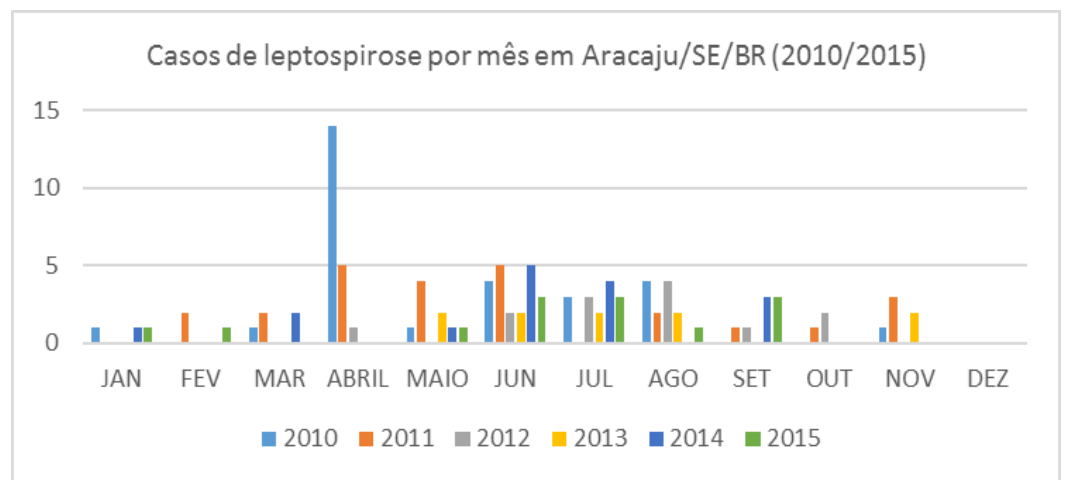

Figura 04. Casos registrados por mês de leptospirose em Aracaju/SE/BR. Fonte: Secretaria Municipal de Saúde de Aracaju/SE (2016). INMET - Estação: ARACAJU SE (OMM: 83096). Org.: CARVALHO, M. E. S; MENDONÇA, F. A.

Os anos de 2010 e 2011 foram os mais chuvosos e concentraram 51\% dos casos (Figura 05). Entre 2012 e 2015 ocorreram os menores totais pluviométricos da série analisada, bem como dos últimos 30 anos, valendo ainda destacar que 2012 e 2015 foram considerados anos de El Niño forte.

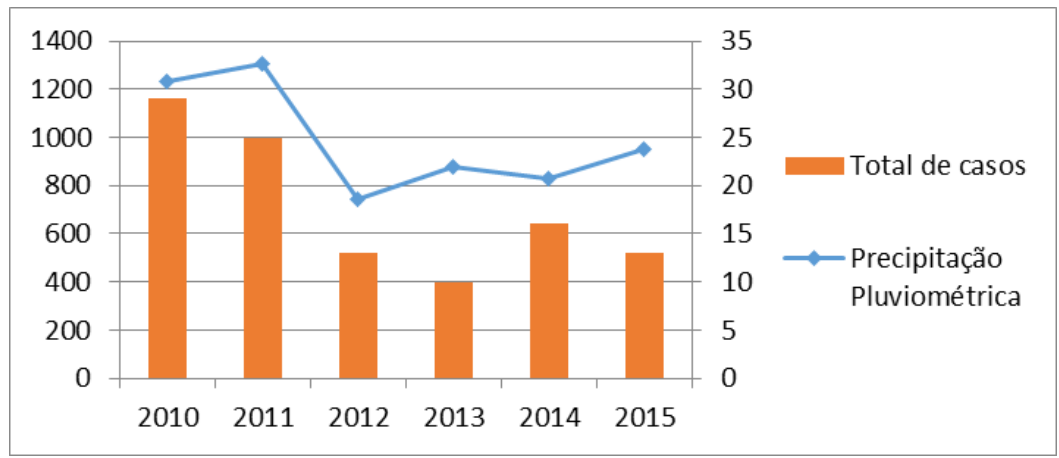

Figura 05. Total de casos de leptospirose em Aracaju/SE/BR (2010-2015).

Fonte: Secretaria Municipal de Saúde de Aracaju/SE (2016). INMET - Estação: ARACAJU - SE (OMM: 83096). Org.: CARVALHO, M. E. S; MENDONÇA, F. A.

Na série temporal em estudo, a correlação mais direta com o aumento do número de casos e os eventos extremos de precipitação (foi considerado o total pluviométrico acima de 50mm precipitado em 24hs) ocorreram em 2010 e 2011, tanto em função da sequência de dias chuvosos, quanto pelo total precipitado em $24 \mathrm{hs}$. Em 2010, por exemplo, $49 \%$ dos casos foram registrados após setes dias de chuvas intensas no mês de abril, que totalizou 293,4mm, 
correspondendo a 78,5\% do total mensal. Neste período ocorreram dois eventos extremos: 10/04/10 - 82mm e 12/04/10 - 76,4mm (Figura 06).

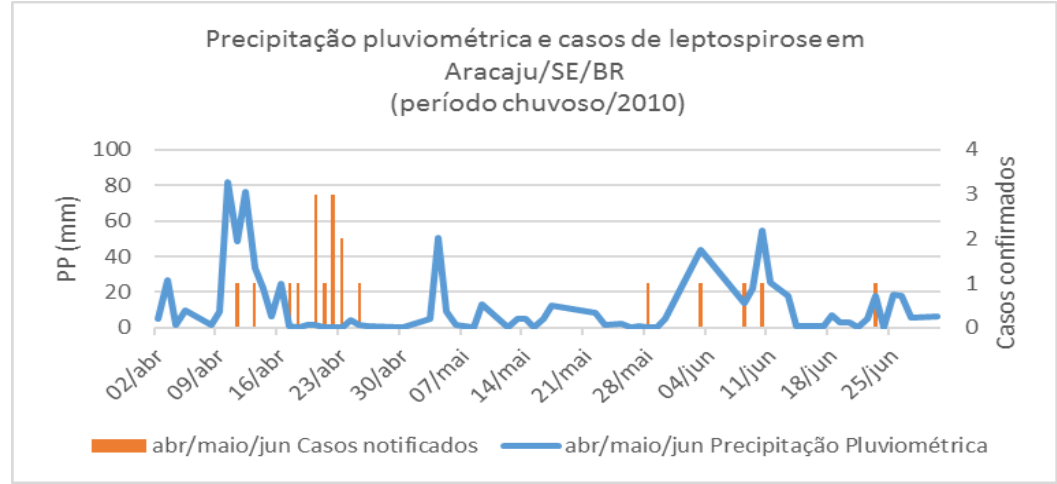

Figura 6: Casos de leptospirose entre abril/junho/2010 em Aracaju/SE/BR. Fonte: Secretaria Municipal de Saúde de Aracaju/SE (2016). INMET - Estação: ARACAJU - SE (OMM: 83096); Org.: CARVALHO, M. E. S; MENDONÇA, F. A.

Seguindo o padrão do ano anterior, 36\% dos casos de 2011 foram registrados após o evento extremo de 25 de maio, o qual precipitou $157 \mathrm{~mm}$ em 24hs (Figura 07).

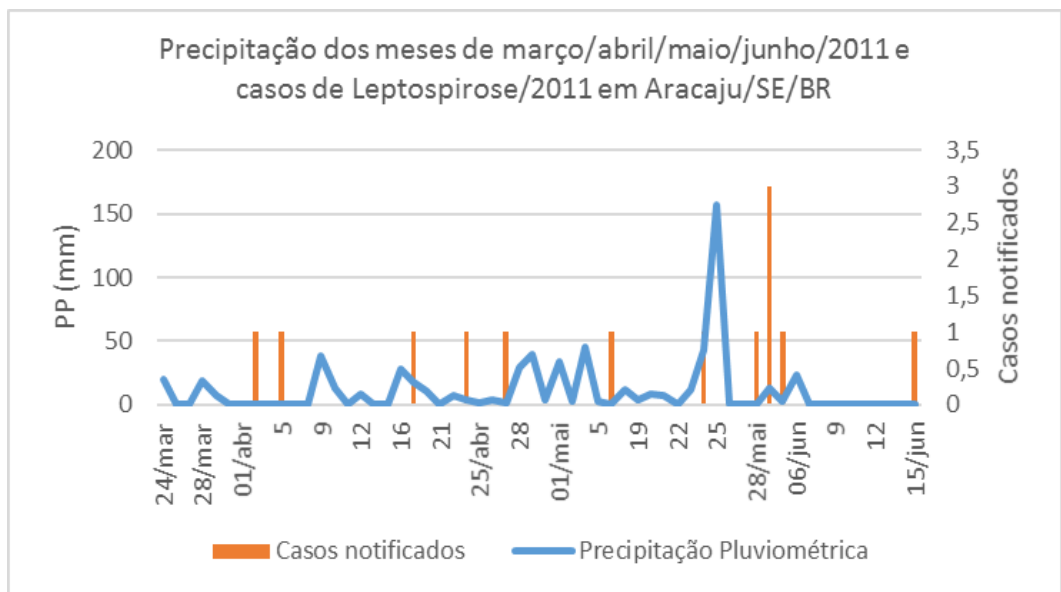

Figura 07. Casos de leptospirose na quadra chuvosa de 2011 em Aracaju/SE/BR

Fonte: Secretaria Municipal de Saúde de Aracaju/SE (2016). INMET - Estação: ARACAJU - SE (OMM: 83096). Org.: CARVALHO, M. E. S; MENDONÇA, F. A.

De acordo com Magalhaes et. al. (2009), os fatores que favorecem o aumento do número de casos de leptospirose estão associados às questões de ordem socioambiental, como a baixa qualidade das habitações, ausência de saneamento básico e 
ocupações em áreas de risco sujeitas a inundações, que são potencializados durante a ocorrência de eventos pluviométricos intensos, fato este constatado nesta pesquisa.

Entre 2012 e 2015 o número de casos foi reduzido o que pode estar associado com a redução dos totais pluviométricos mensais. Entretanto foi mantido o padrão de ocorrência dos casos na quadra chuvosa.

Mesmo considerando o tempo entre a ocorrência das chuvas e o contato do indivíduo com a água contaminada, que pode variar entre um a trinta dias para a doença se manifestar, ao aplicar o coeficiente de correlação de Pearson, foi identificada correlação alta, 0,779, entre os casos notificados de leptospirose e a ocorrência de chuva por mês na série temporal analisada e correlação também alta por total de casos por ano $(0,870)$. Estes resultados corroboram com pesquisas desenvolvidas tanto no Nordeste do país (MAGALHÃES, et.al. 2009) quanto no Sul (BUFFON e MENDONÇA, 2014).

Por outro lado, difere do obtido por Melo (2011) que a partir de dados anuais de registro dos casos de leptospirose e total pluviométrico de 2001 a 2007, afirmou que não havia, em seu estudo em Aracaju/SE, correlação entre o padrão de ocorrência das chuvas e os casos notificados. Destaca-se então a importância da identificação da ocorrência não somente pelo total anual, mas principalmente pela data de registro dos primeiros sintomas, conforme a pesquisa em tela está apresentando.

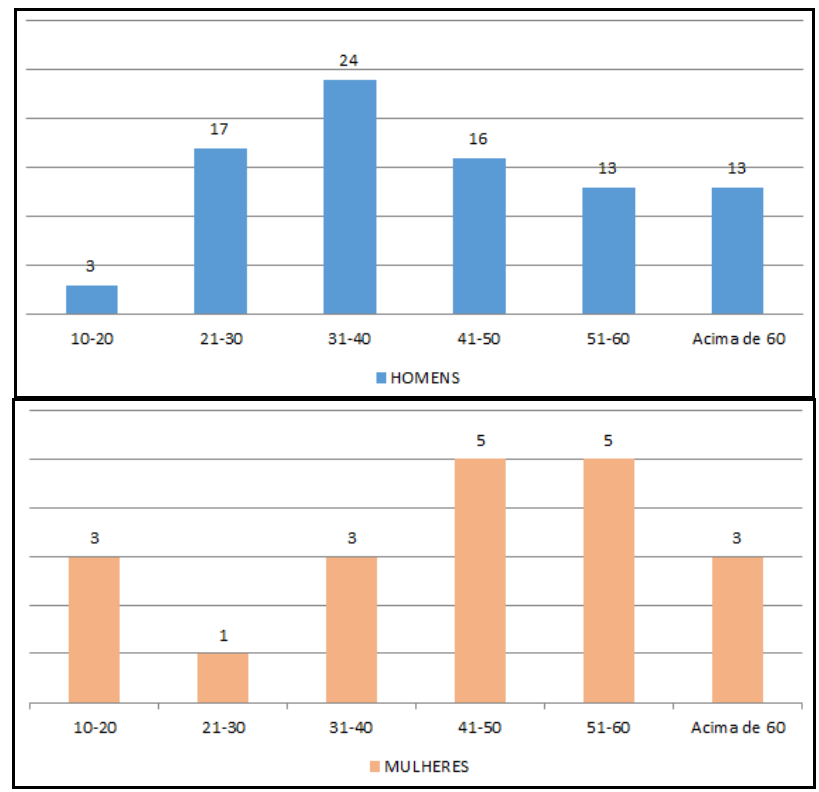

Figura 08. Distribuição por gênero e faixa etária dos casos notificados de leptospirose (2010 a 2015).

Fonte: SMS de Aracaju (2016). Org.: Luan L. Ramos. 


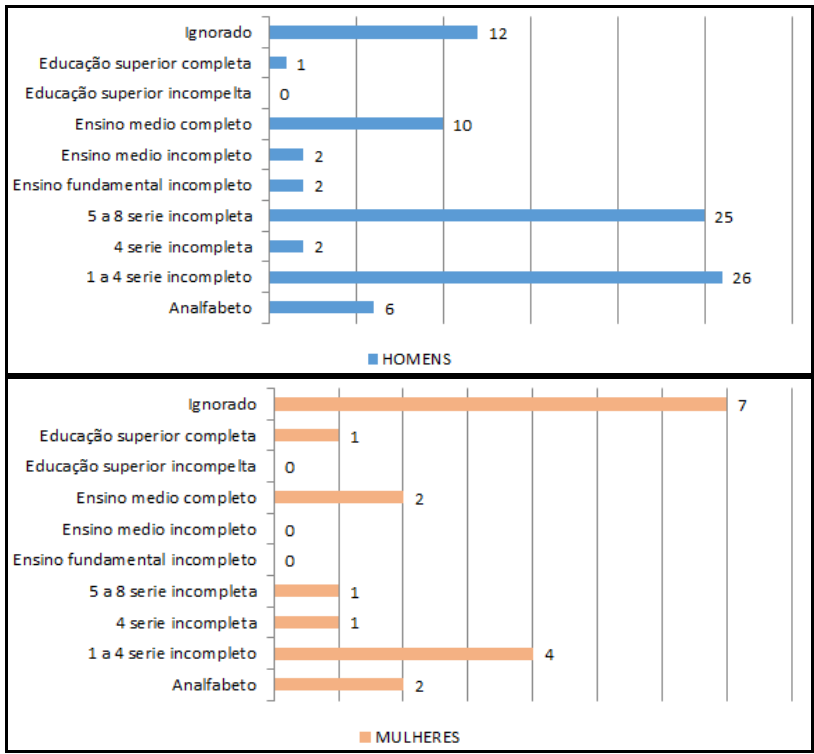

Figura 09. Grau de escolaridade por gênero dos casos notificados de leptospirose (2010 a 2015)

Fonte: SMS de Aracaju (2016); Org.: Luan L. Ramos

Com relação ao perfil dos casos notificados, $81,7 \%$ são do sexo masculino, sendo que $47,6 \%$ na faixa etária entre 21 e 40 anos, perfazendo o perfil economicamente ativo, com baixa formação educacional totalizando $61,6 \%$ com o ensino fundamental incompleto (Figura 08 e 09).

No tocante a espacialização do local de residência da pessoa infectada, $87 \%$ dos casos foram notificados em bairros periféricos da cidade, nas zonas norte e oeste, nos quais predominam a menor renda família e a menor cobertura em termos de esgotamento sanitário de Aracaju, sendo os bairros Santa Maria, Santos Dumont e Lamarão os que apresentaram o maior número de casos de leptospirose ao longo de toda a série pesquisada (Figura 10).

Em termos de incidência, o bairro Lamarão apresentou o maior índice, seguido pelos bairros Jardim Centenário, Santa Maria e Santos Dumont ratificando que os condicionantes socioambientais associados a pobreza tornam determinada comunidade mais vulnerável ao processo saúde-doença (Figuras 11, 12, 13).

Tal realidade demonstra também que no tocante as políticas públicas de saúde coletiva as ações intersetoriais necessitam ser ampliadas, pois o tratamento pontual dos casos torna-se um elemento paliativo, sendo que a cada ocorrência de novos eventos extremos de precipitação novos surtos estarão sendo associados, acometendo a população de mais baixa renda, localizada nos bairros com a rede de saneamento mais 
deficitária. Assim, embora havendo a notificação e o tratamento, o sujeito retorna a sua realidade socioambiental podendo estar novamente em situação de risco.
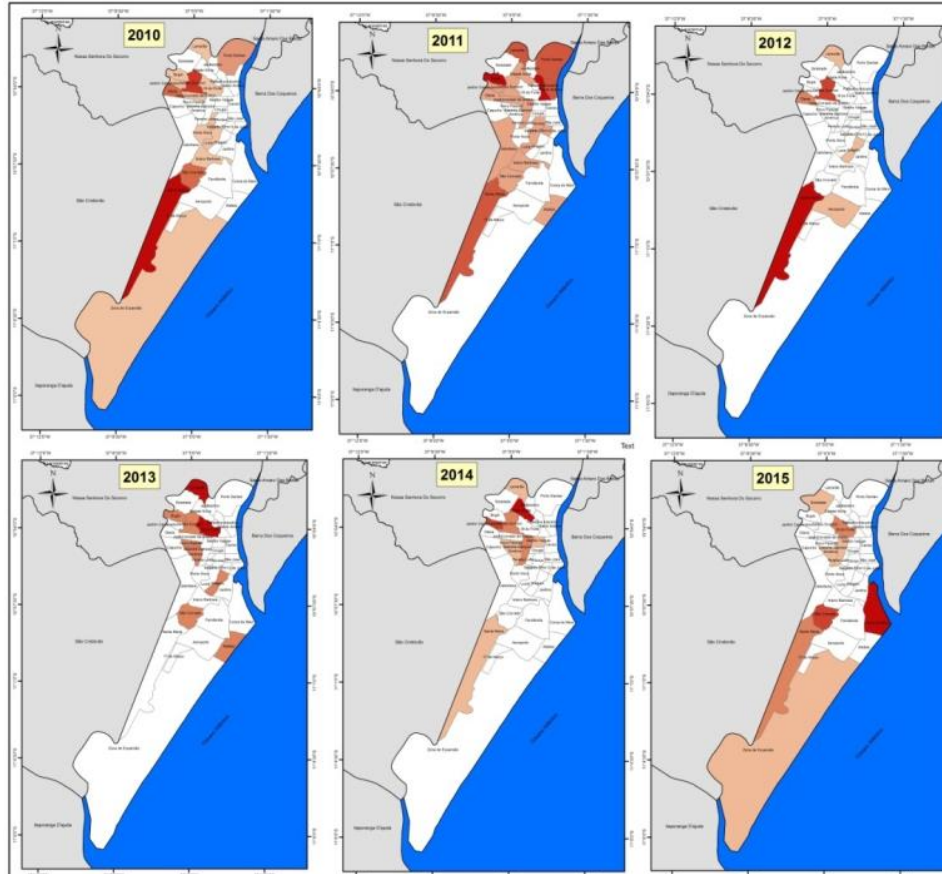

NOTIFICAÇÕES DE LEPTOSPIROSE ARACAJU-SE 2010-2015

Figura 10. Notificações de casos de leptospirose por ano em Aracaju/SE/BR (2010-2015) Fonte: Secretaria Municipal de Saúde de Aracaju; Org.: GOIS, D. V.

Esta realidade nos remete as considerações de Valadares e Lima (2015, p.461):

...a saúde centra-se no padrão biomédico, bem como nas medidas hospitalocêntricas, que não agregam nenhum fator psicossocial ao tratamento, por enfatizarem apenas a doença em si, controlando-a para que o indivíduo retroceda ao estado de não doença. Mas, o paciente apenas analisado e considerado à ótica de sua patologia tem sua dignidade, potencialidades, responsabilidade e diretos sociais, um a um, negligenciados. Ora, da saúde não pode ser entendimento unicamente como processo patológico, na medida em que indubitavelmente existem aspectos biopsicossociais.

Considerando estes aspectos, há necessidade de se rever o modelo biomédico, centrado na doença e ampliar a leitura para o componente social e ambiental, integrando a tríade dos estudos no campo da geografia da saúde, que segundo Pickenhayn (2009, p.16) abrange três questões fundamentais: 
... la salude, el ambiente y lasociedad. Ciências de vocación social ambas, la geografia y la medicina comparten este plexo em el que miríadas de filamentos enlazadosoriginan uma malla sensitiva. Uma especialidad de cada uma de ellas, la geografia de lasalud y laepistemiolgia, respectivamente, generan esta suerte de proyección cruzada: elespcio como tema médico, por um lado; lasalud como tema geográfico, por el outro. Esta superposición, empero, está lejos de ser um obstáculo. enel presente, latransdisciplinariedad permite que cada tema generesu próprio perfil de ciência...

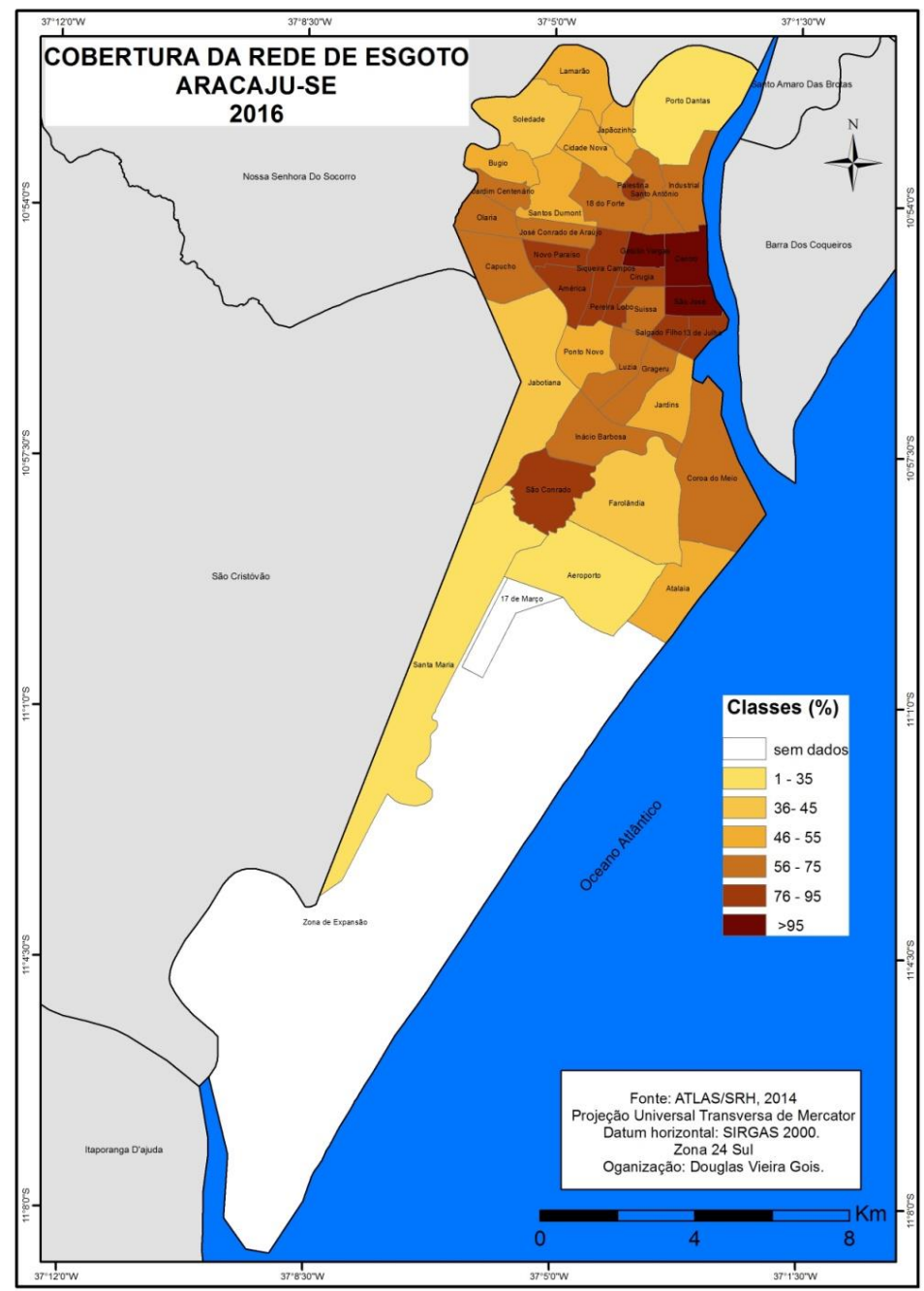

Figura 11. Rede de esgoto de Aracaju/SE/BR (2010).

Fonte: IBGE (2010). Org.: GOIS, D. V. 


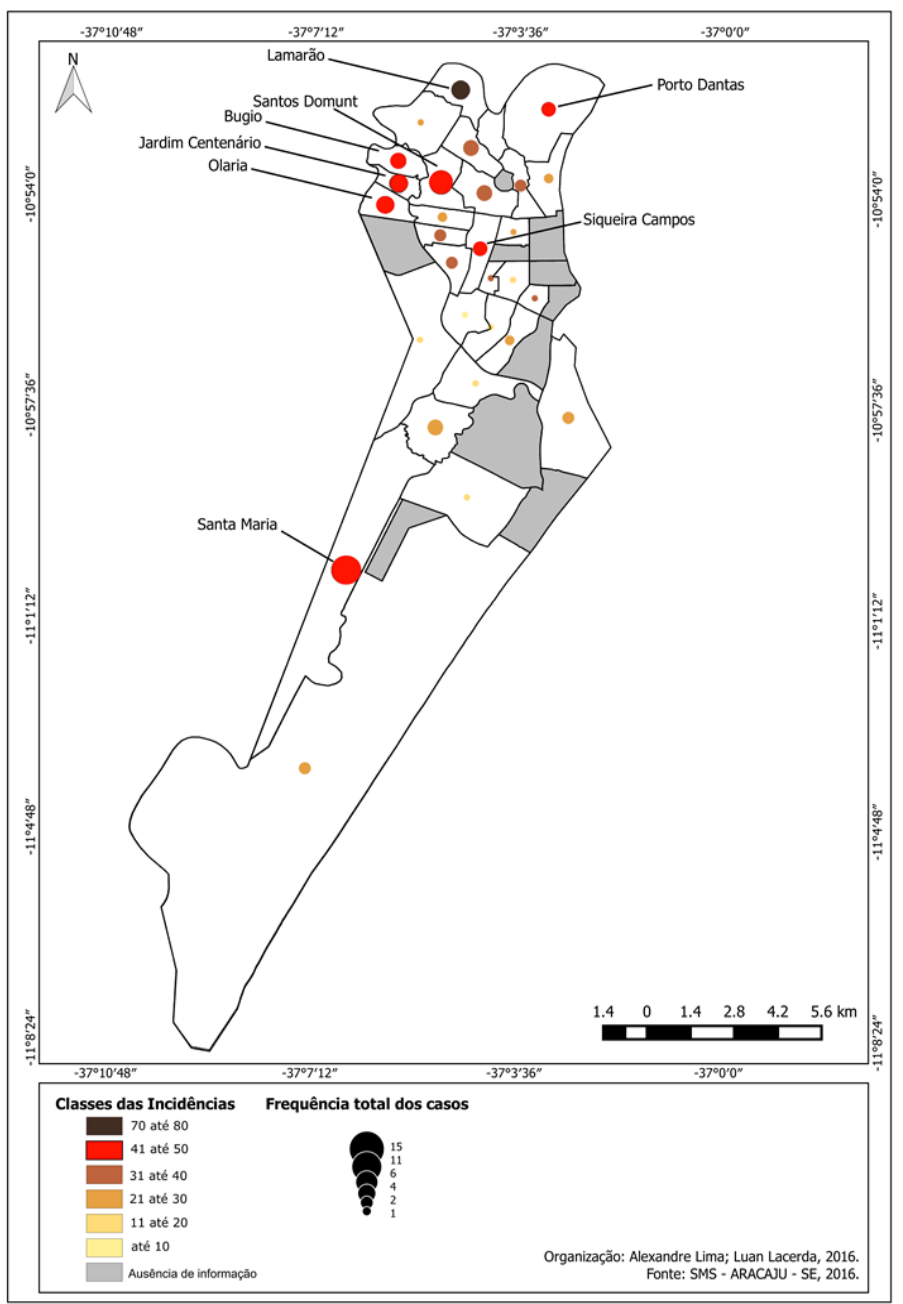

Figura 12. Incidência e Frequência total da leptospirose em Aracaju/SE/BR(2010-2015).

Fonte: PMA (2016), SEMARH/SRH; Org.: LIMA, A.; LACERDA, L. 


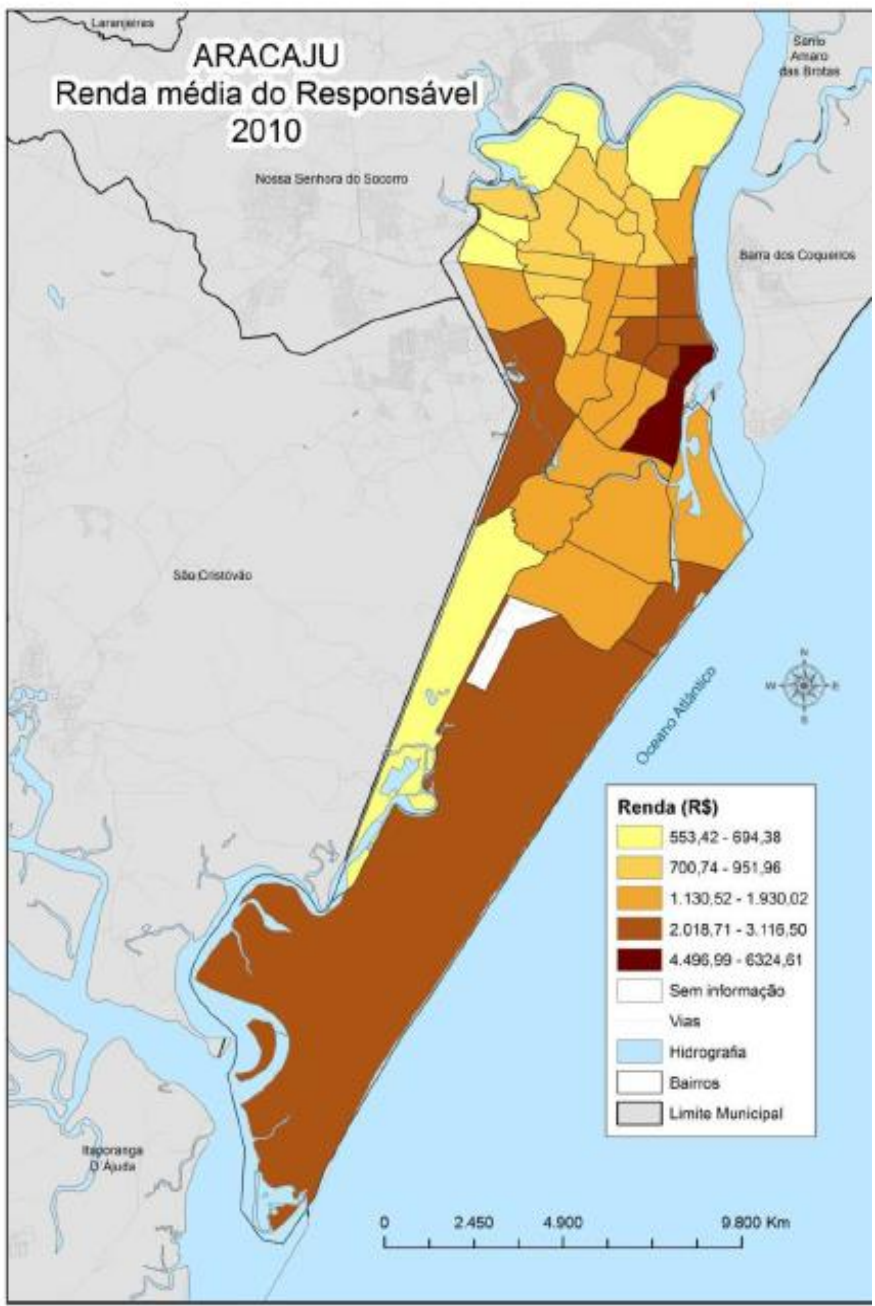

Figura 13. Renda média do Responsável em Aracaju/SE/BR (2010).

Fonte: SERGIPE (2010).

Por outro ângulo de análise, Pereira (2014) estimou o custo social dos casos de leptospirose notificados em 2008 no Brasil, constatando que os 3.492 casos de leptospirose ocorridos em 2008 geraram ao Sistema de Saúde um custo estimado de $\mathrm{R} \$ 1.542 .526,92$, tendo sido perdidos $10.664,90$ anos potenciais de vida, havendo perda também de renda da ordem de $\mathrm{R} \$ 27.744 .133,33$, além da perda de produtividade que variou entre $\mathrm{R} \$ 278.481,60$ e $\mathrm{R} \$ 979.317,00$, apenas para 2008. 
Estes valores nos mostram a necessidade de ações intersetoriais que considerem a prevenção e qualidade ambiental e de vida como meta a ser perseguida no sentido da busca do real sentido da saúde ambiental e coletiva, conforme destaca Moreira e Lobos (2011, p. 184):

A saúde ambiental resulta da interação de diversos fatores que operam em distintos níveis de agregação e no contexto dos processos complexos que vão além dos componentes biológicos, físicos e químicos tradicionais do meio ambiente. Esses fatores, de natureza social, econômica, política, ambiental, tecnológica e biológica, podem se relacionar mutuamente ou em conjunto, gerando fatores intermediários que influenciam na saúde e no bemestar das populações.

\section{Zonas de risco à leptospirose em Aracaju}

Considerando o banco de dados analisado, $95,4 \%$ dos casos apresentaram como área provável da infecção a zona urbana, ratificando que a população residente em aglomerados urbanos desordenados e de baixa renda, em diferentes capitais brasileiras, são acometidas por diversos impactos, estando mais vulneráveis a doenças.

As desigualdades urbanas da cidade de Aracaju foram ratificadas quando foi realizada a modelagem geoespacial para definir as zonas de risco para a leptospirose. Foi utilizado para compor o banco de dados a renda (R), a rede de esgoto (RE), o tipo de pavimentação (TP) e a ocorrência de alagamentos (A). Para cada um destes indicadores foi dado um valor entre 1 e 10 no qual um significa a melhor situação e dez caracteriza a situação mais degradante da variável em análise (Quadro 01).

Quadro 01: Indicadores, variáveis e valoração para determinar o peso em cada endereço georreferenciado no qual foi notificado caso de leptospirose em Aracaju

\begin{tabular}{|c|c|c|c|}
\hline Indicador & Variáveis & Valoração & Fonte \\
\hline \multirow{6}{*}{ 1.Renda média do responsável } & $<1$ salário mínimo & 10 & \multirow{6}{*}{$\begin{array}{l}\text { IBGE, 2010; } \\
\text { Sergipe } \\
(2010)\end{array}$} \\
\hline & Até 1 salário mínimo & 8 & \\
\hline & $>1$ salário mínimo a 2 salários mínimos & 6 & \\
\hline & > 2 salários mínimos a 3 salários mínimos & 4 & \\
\hline & > 3 salários mínimos a 4,5 salários mínimos & 2 & \\
\hline & > 4,5 salários mínimos & 1 & \\
\hline \multirow{5}{*}{ 2.Cobertura rede de esgoto } & $<35 \%$ & 10 & \multirow{5}{*}{ IBGE, 2010} \\
\hline & $>35 \% \mathrm{a}<55 \%$ & 8 & \\
\hline & $>55 \% \mathrm{a}<75 \%$ & 6 & \\
\hline & $>75 \% \mathrm{a}<95 \%$ & 4 & \\
\hline & $>95 \%$ & 1 & \\
\hline
\end{tabular}




\begin{tabular}{|c|c|c|c|}
\hline Indicador & Variáveis & Valoração & Fonte \\
\hline \multirow{3}{*}{$\begin{array}{l}\text { 3.Tipo de pavimentação das } \\
\text { ruas }\end{array}$} & $\begin{array}{l}\text { Ruas sem nenhum tipo de pavimentação e } \\
\text { com bueiros/esgoto a céu aberto }\end{array}$ & 10 & \multirow{3}{*}{$\begin{array}{l}\text { Pesquisa de } \\
\text { campo; } \\
\text { Google } \\
\text { Earth }\end{array}$} \\
\hline & Parcialmente pavimentadas & 5 & \\
\hline & $\begin{array}{l}\text { Rua pavimentada sem bueiros/esgoto a céu } \\
\text { aberto }\end{array}$ & 1 & \\
\hline \multirow{4}{*}{$\begin{array}{l}\text { 4.Alagamentos - Episódios de } \\
\text { alagamentos no período em } \\
\text { estudo }\end{array}$} & Mais de 7 episódios & 10 & \multirow{4}{*}{$\begin{array}{l}\text { EMURB } \\
(2013) ; \\
\text { Brazil } \\
(2016)\end{array}$} \\
\hline & 5 a 7 episódios & 6 & \\
\hline & De 1 a 4 episódios & 3 & \\
\hline & Sem a ocorrência & 1 & \\
\hline
\end{tabular}

Org.: CARVALHO, M. E. S.; MENDONÇA, F. A.

Estes indicadores foram selecionados por serem considerados como condicionantes para ampliar o risco socioambiental. O tipo de coleta de lixo não foi inserido, visto que há deficiência nos dados oficiais no tocante a realidade de cada bairro pesquisado, o que poderia mascarar a realidade em análise.

Os endereços foram todos georreferenciados, sendo que $15 \%$ dos mesmos não puderem ser identificados por estarem incompletos ou apresentando erros de localização. Para os demais, foi definida a valoração de cada um dos casos notificados de acordo com a metodologia detalhada no item encaminhamentos metodológicos, sintetizada no quadro 01 (Tabela 02).

Tabela 02. Valores atribuídos a cada endereço georreferenciado no qual foram notificados casos de leptospirose.

\begin{tabular}{|c|c|c|c|c|c|}
\hline Pontos & Valoraçã $^{\text {** }}$ & Pontos & Valoração* $^{*}$ & Pontos & Valoração* $^{*}$ \\
\hline 1 & 5,25 & 31 & 7,25 & 61 & 4 \\
\hline 2 & 10 & 32 & 3,5 & 62 & 5,75 \\
\hline 3 & 4 & 33 & 5,25 & 63 & 6,5 \\
\hline 4 & 5,75 & 34 & 3 & 64 & 5,25 \\
\hline 5 & 5 & 35 & 6 & 65 & 4 \\
\hline 6 & 5 & 36 & 8,75 & 66 & 5 \\
\hline 7 & 5 & 37 & 6 & 67 & 6,5 \\
\hline 8 & 7,75 & 38 & 6 & 68 & 6,75 \\
\hline 9 & 10 & 39 & 6,75 & 69 & 6,75 \\
\hline 10 & 4,25 & 40 & 2,5 & 70 & 5 \\
\hline 11 & 5,25 & 41 & 6,25 & 71 & 6,75 \\
\hline
\end{tabular}

\footnotetext{
1 * Valores entre 1 e 10 no qual um significa a melhor situação e dez caracteriza a situação mais degradante da variável em análise
} 


\begin{tabular}{|c|c|c|c|c|c|}
\hline Pontos & Valoração* & Pontos & Valoração* & Pontos & Valoração* $^{*}$ \\
\hline 12 & 4,5 & 42 & 6,75 & 72 & 3 \\
\hline 131 & 10 & 43 & 6,5 & 73 & 7 \\
\hline 14 & 7,25 & 44 & 7,25 & 74 & 4 \\
\hline 15 & 8,75 & 45 & 3,5 & 75 & 6 \\
\hline 16 & 5 & 46 & 8,25 & 76 & 7 \\
\hline 17 & 6 & 47 & 5 & 77 & 3 \\
\hline 18 & 6,5 & 48 & 6 & 78 & 8,75 \\
\hline 19 & 7,25 & 49 & 6,25 & 79 & 6,5 \\
\hline 20 & 6 & 50 & 6,3 & 80 & 6 \\
\hline 21 & 7,25 & 51 & 4 & 81 & 6,75 \\
\hline 22 & 4,5 & 52 & 8,75 & 82 & 6,3 \\
\hline 23 & 7,25 & 53 & 6 & 83 & 5,5 \\
\hline 24 & 5 & 54 & 8,25 & 84 & 8,75 \\
\hline 25 & 4 & 55 & 8,75 & 85 & 4 \\
\hline 26 & 6 & 56 & 7,75 & 86 & 3 \\
\hline 27 & 7,25 & 57 & 5,5 & 87 & 4 \\
\hline 28 & 5,25 & 58 & 6 & 88 & 5,5 \\
\hline 29 & 5,25 & 59 & 5 & 89 & 7,25 \\
\hline 30 & 5,25 & 60 & 5,5 & - & - \\
\hline
\end{tabular}

Org.: CARVALHO, M. E. S.; MENDONÇA, F. A.

A modelagem revelou a ocorrência de três zonas claramente definidas no contexto urbano de Aracaju: uma zona de elevado risco à leptospirose, outra de médio e a terceira de baixo risco (Figura14).

A zona de alto risco corresponde aos bairros periféricos da cidade de Aracaju abrangendo as zonas norte e a periferia sociológica da zona sul, nos quais predomina a menor renda familiar, menor cobertura da rede de esgoto, ocorrência frequente de alagamentos, maior área com rede de drenagem superficial exposta e precariedade em termos de pavimentação, sendo os bairros Santa Maria, Santos Dumont e Lamarão os que apresentaram o maior número de casos de leptospirose. É a zona com o mais elevado nível de risco socioambiental. No computo total são 207.238 pessoas vivendo nesta zona de alto risco. 


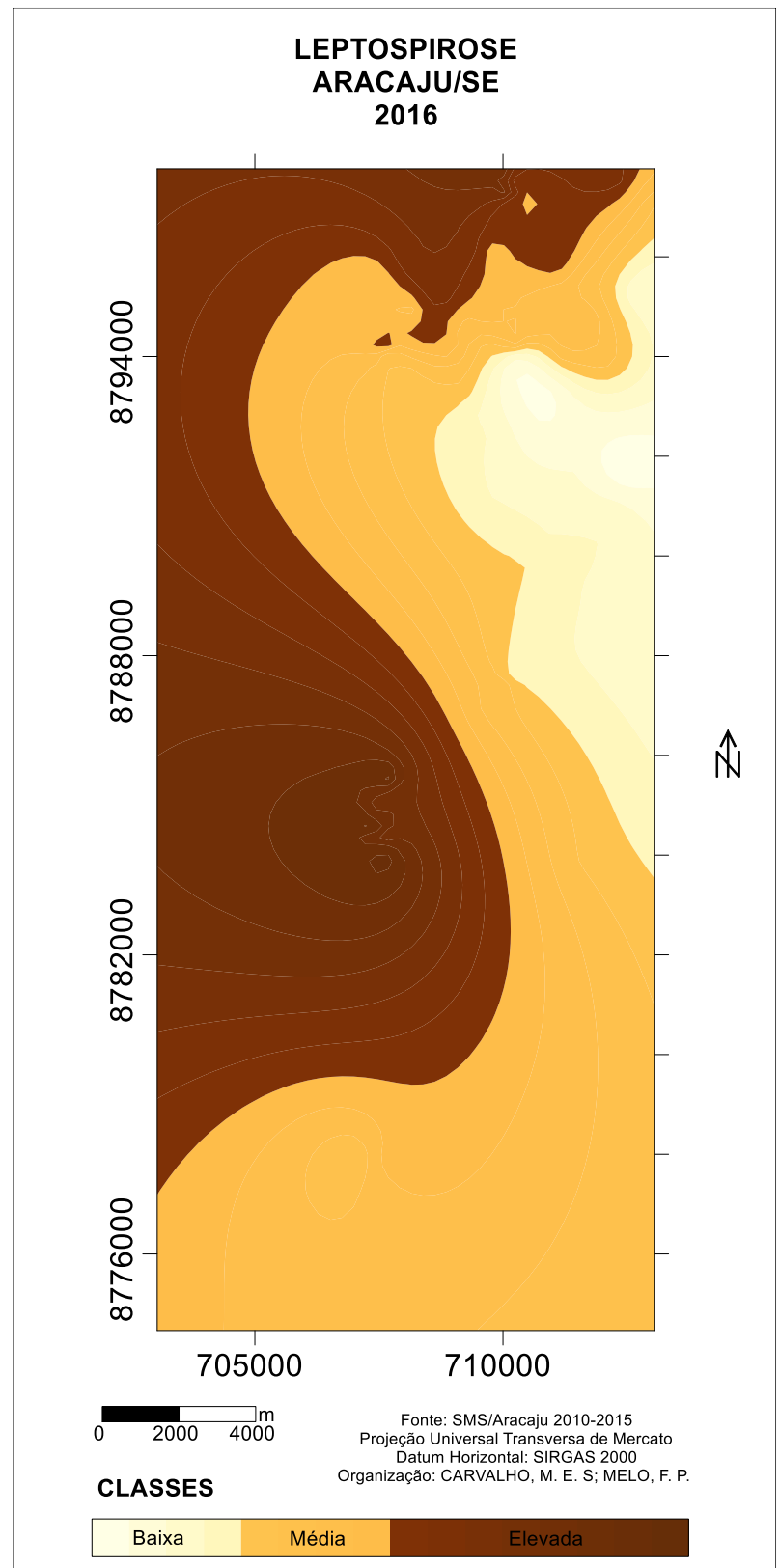

Figura 14. Zonas de risco para a Leptospirose em Aracaju/SE

Fonte: SMS/Aracaju 2010-2015; Org.: CARVALHO, M. E. S.; MELO, F. P. 
Trazendo um olhar ampliado para os riscos socioambientais desta zona, Fonseca et.al. (2010) realizou mapeamento sobre as condições socioambientais dos bairros de Aracaju e avaliou características relacionadas a renda, condições prediais, uso do solo, qualidade do saneamento, das áreas de lazer e das vias de circulação estratificando a matriz final em uma escala de 1 a 5 , na qual cinco é a melhor condição atribuída ao bairro. Os resultados apontaram que os mais baixos índices $(1,9$ a 2,2) foram mensurados para os bairros Lamarão e Porto Dantas, na zona norte de Aracaju, e Santa Maria e Zona de Expansão, na zona periférica sul da cidade.

Desta forma, a pesquisa aqui apresentada, vem somar mais uma variável a análise: os referidos bairros também se encontram na zona de risco à leptospirose, ratificando que "...na realidade, de há muito se sabe que a distribuição da saúde e da doença nas populações não é aleatória e que obedece à estratificação socioeconômica dos grupos populacionais (PELLEGRINI FILHO e BUS, 2011, p. 589).

A análise dos componentes ambientais associados aos condicionantes socioeconômicos revelados nesta pesquisa vem ratificar as ponderações de Oliveira (2009a), sobre o modelo de produção da leptospirose, que deve considerar toda a sua cadeia produtiva: reservatório, ambiente, fatores demográficos e socioeconômicos. Considerando a impossibilidade de erradicação do transmissor, o conhecimento destas associações vem somar esforços aos serviços de saúde coletiva no sentido de centrar ações na busca de uma leitura intersetorial para minimizar o risco de contaminação.

As variáveis mais negativas na valoração dos pesos de cada endereço desta primeira zona foram a renda e o número de alagamentos. Minimizado estas duas variáveis, foi delimitada então a zona de médio risco.

A zona de médio risco situa-se na região de transição entre as de alto e baixo risco, apresentando melhorias principalmente no tocante ao nível de renda e condições de infraestrutura, com poucos casos notificados de leptospirose, tendo sido estes os fatores que influenciaram na delimitação desta zona. Abrange parte da zona sul, parte da zona oeste e parte do centro, a exemplo dos bairros Aeroporto, Inácio Barbosa, Jabotiana, Ponto Novo e Getúlio Vargas.

Compreende-se desta forma que os riscos não estão dispostos igualmente para todos. A expressão espacial e a escala temporal de produção do espaço urbano ganham relevância neste tipo de análise. Para Mendonça (2011):

Uma das principais dimensões dos riscos, e de interesse das sociedades, é sua expressão espacial, ou seja, os riscos são espacial e temporalmente datados, o que os torna um dos temas de maior interesse da geografia atual. Neste aspecto não se trata de abordálos de um ponto de vista apenas natural ou social, ainda que se possa fazê-lo, mas de buscar evidenciar sua expressão geográfica tendo por base a imbricação direta dos diferentes elementos componentes do espaço geográfico. 
A zona de baixo risco abrange os bairros mais antigos da capital e de padrão mais elevado em termos de renda e consequentemente com o melhor e mais abrangente tipo de infraestrutura, podendo ser considerada uma zona na qual são pouco expressivos os riscos socioambientais. Nesta zona, o nível de ocorrência da leptospirose variou de zero a um. Abrange os bairros como Jardins, 13 de Julho, São José, Centro, Cirurgia.

Este zoneamento retrata a segregação socioespacial urbana de Aracaju. A população das periferias das zonas norte e sul (periferia sociológica) apresentam elevado risco de serem infectadas pela leptospirose quando se associa a localização dos casos notificados, nível de renda, sistema de rede de esgoto, número de alagamentos (que potencializam os riscos de contaminação e disseminação da doença) e infraestrutura do bairro, o que gera um alerta para o fato de que as políticas setorizadas não podem solucionar os problemas associados a saúde de forma independente sem haver uma interlocução com a melhoria na qualidade ambiental e de vida daquelas comunidades.

Estes resultados coadunam com as pesquisas realizadas por Oliveira (2009b) na cidade do Recife, que identificou desigualdades intraurbanas e concentração espacial da leptospirose na referida cidade, reforçando a necessidade de políticas voltadas à redução das iniquidades em saúde e necessidade de escolha de áreas prioritárias de intervenção. De acordo com o estudo da autora, as taxas de incidência e de mortalidade por leptospirose apresentaram gradiente crescente com o aumento do risco socioambiental.

Por fim, entende-se que o uso de softwares tanto para a identificação da incidência quanto para a zonas de risco apresentaram uma contribuição a análise espacial do processo saúde/doença e seus condicionantes socioambientais, pois “... as técnicas de geoprocessamento e os modelos de análise para distribuições espaciais podem fornecer novas ferramentas para a descrição de doenças em população" (BARRADAS, 1999, p.13). O uso de ferramentas de geoprocessamento no entendimento dos processos de saúde-doença pode contribuir para ampliar as inter-relações entre os componentes ambientais e sociais, direcionando as ações em saúde coletiva de forma mais efetiva.

\section{Considerações Finais}

Os modelos elaborados para a identificação da incidência associada com a frequência bem como o modelo para delimitar as zonas de risco à leptospirose em Aracaju, demonstraram que a aplicação de softwares de geoprocessamento na área de saúde, especificamente para a investigação epidemiológico-geográfica, foi além da localização potencial dos casos de morbidade e mortalidade pois permitiu

... integrar e converter a mera descrição das características económicas e sócio-demográficas da população em risco em ferramentas explicativas, onde o espaço e as dinâmicas subjacentes, social e politicamente produzidas, emergem como determinantes inteligíveis ao nível da modelação dos processos de saúde das populações (NOSSA, 2012, p. 139) 
Desta forma, foi possível o reconhecimento de áreas de risco do ponto de vista socioambiental, nas quais ocorreu a concentração da doença, tornando-se importante lócus para as ações de controle de endemias desde que integradas a outras políticas públicas voltadas para melhoria no saneamento, habitação, educação e distribuição de renda.

Concorda-se com Oliveira (2009) ao afirmar que no Brasil a leptospirose necessita ser reconhecida como um problema de saúde pública e ainda mais como uma doença negligenciada da pobreza, visto que as condições ecológicas para a existência de roedores no ambiente urbano, associado com as desigualdades sociais e precárias condições socioambientais nas quais residem populações de baixa renda, favorecem a prevalência da doença no ambiente, ocasionando surtos após os eventos extremos de precipitação.

A correlação entre os eventos extremos de precipitação com o aumento dos casos de leptospirose foi considerado alto, espacialmente nos bairros periféricos da cidade e que apresentam a menor renda familiar de toda a capital, as mais baixas taxas de cobertura de esgoto e de infraestrutura de pavimentação, o que permite afirmar que a comunidade está exposta aos riscos climáticos potencializados pela condição de vulnerabilidade socioambiental.

Vale destacar também que a rede de drenagem urbana da cidade é deficiente, com contaminação das águas pluviais com esgoto devido à falta da rede coletora separadora, fato que se agrava com ocupação urbana desordenada.

Este agregado de itens e a delimitação das zonas de risco demonstra que a redução dos casos de leptospirose necessita de ações intersetoriais no âmbito social, interligadas com a saúde, saneamento, habitação, limpeza urbana e educação em saúde. Ações isoladas pouco contribuirão para evitar novos casos que atingem principalmente a população mais vulnerável do ponto de vista socioambiental.

\section{Referências}

BARCELLOS, C. et. al. Mudanças climáticas e ambientais e as doenças infecciosas: cenários e incertezas para o Brasil. Epidemiologia e Serviços de Saúde, Brasília, v. 18, n. 3, p.285-304, jul-set. 2009.

BARCELLOS, C.; SABROZA, P. C. The place behind the case: leptospirosis risks and associated environmental conditions in a flood-related outbreak in Rio de Janeiro. Cadernos de Saúde Pública, Rio de Janeiro, v.17(Suplemento), p. 59-67, 2001.

BARRADAS, R. de C. B. O Desafio das Doenças Emergentes e a Revalorização da Epidemiologia Descritiva. Informe Epidemiológico do SUS, Brasília, v. 8, n. 1, p.7-15, 1999.

BRAZIL, J. L. S. Eventos pluviais extremos e risco de inundações na cidade de Aracaju/SE. Dissertação de Mestrado. São Cristóvão: PPGEO/UFS, 2016. 
CARLOS, A.F.A. O Espaço urbano: novos escritos sobre a cidade. São Paulo: FFLCH, 2007.

CONFALONIERI, U. E. C. Variabilidade climática, vulnerabilidades social e saúde no Brasil. Terra Livre, São Paulo, vol. 1, n. 20, p. 193-204 jan/jul, 2003.

DATASUS. Notificação de casos de leptospirose de 2001-2010. 2016

FONSECA, V. et.al. Mapeamento socioambiental como ferramenta para análise das relações espaciais: os bairros de Aracaju. GEONORDESTE, Ano XXII, n.1, p. 148-179. 2010.

IBGE. Censo demográfico. Brasília, 2010.

INMET. Gráficos Climatológicos. 2016. Disponível em:

$<$ http://www.inmet.gov.br/html/clima.php>. Acesso em 17.03.2016.

MELO, F. P. de, et al. Modelagem de geoformas para mitigação do risco geoambiental em Garanhuns-PE. ACTA Geográfica, Boa Vista, v.10, n.22, p.87-105, jan./abr. 2016.

MENDONÇA, F. Clima, tropicalidade e saúde: uma perspectiva a partir da intensificação do aquecimento global. Revista Brasileira de Climatologia, vol. 1, n. 1, p.100-112. 2005.

MENDONÇA, F. Riscos, vulnerabilidades e resiliência socioambientais urbanas: inovações na analise geográfica. Revista da ANPEGE, v. 7, n. 1, número especial, p. 111-118, out. 2011.

MOREIRA, J. C.; LOBOS, J. O papel e os desafios dos laboratórios de saúde ambiental nas Américas. In: GALVÃO, Luiz Augusto C.; et.al. Determinantes ambientais e sociais da saúde. Rio de Janeiro: Organização Pan-Americana da Saúde/FIOCRUZ, 2011, p. 183-196.

NOSSA, P. Saúde e Espaço. Porto: Edições Afrontamento, 2012.

OLIVEIRA, D. S. C. de. Modelo produtivo para a leptospirose. Revista de Patologia Tropical. Goiânia, v. 38, n. 1, p. 17-26, jan.-mar. 2009a.

OLIVEIRA, D. S. C. de. Desigualdades Intraurbanas de Leptospirose no Recife. Tese de Doutorado. Centro de Pesquisas Aggeu Magalhães, Fundação Oswaldo Cruz. Recife, 2009b.

PELLEGRINI FILHO, A; BUS, P.M. O movimento dos determinantes sociais da saúde no Brasil. In: GALVÃO, L.A. et.al. Determinantes ambientais e sociais da saúde. FIOCRUZ/OMS, 2011. p. 589-601.

PEREIRA, C. A. R. Custo social da leptospirose no Brasil e o efeito de chuvas extremas em Nova Friburgo para o incremento de casos da doença. Dissertação Mestrado. Escola Nacional de Saúde Pública Sergio Arouca, Rio de Janeiro, 2014. 
PICKENHAYN, J.A. Salud e enfermedad em geografia. Buenos Aires. Lugar, 2009.

SERGIPE. Diagnóstico socioeconômico de Aracaju. Plano Diretor de Aracaju. 2010.

SMS. Secretaria Municipal de Saúde de Aracaju/SE. Notificação de casos de leptospirose em Aracaju de 2010 a 2015.

SRH. Atlas Digital de Recursos Hídricos de Sergipe. Sergipe, 2014.

VALARARES, R.; LIMA, S. C. O acesso à saúde: de objeto a sujeito de direito transformador do território. Anais... VII Simpósio Nacional de Geografia da Saúde, Brasília: UNB, 2015, p. 453-462.

TUCCI, C. E. M. Águas Urbanas. Estudos avançados. São Paulo, v. 22, n. 63, p. 97-112. 2008

\begin{abstract}
Márcia Eliane Silva Carvalho
Pós-doutorado em Geografia da Saúde pela Universidade Federal do Paraná. Doutorado e Mestrado em Geografia pela Universidade Federal de Sergipe. Graduação em Ciências Biológicas pela Universidade Federal de Sergipe. Atualmente é professora associada do Departamento de Geografia da Universidade Federal de Sergipe, onde também atua no Programa de Mestrado Profissional em Rede Nacional para o Ensino das Ciências Ambientais (PROF-CIAMB).

Universidade Federal de Sergipe - Avenida Marechal Rondon, s/n, Rosa Elze. CEP: 49100-000, São Cristóvão/SE.

E-mail: marciacarvalho_ufs@yahoo.com.br

\section{Francisco de Assis Mendonça}

Pós-doutorado em Estudo do ambiente urbano - Universidad de Chile - 2014 e em Epistemologia da Geografia - Université Sorbonne/Paris I/França - 2005. Doutorado e Mestrado em Geografia pela USP. Graduação em Geografia pela Universidade Federal de Goiás. É Professor Titular do Departamento de Geografia da UFPR, atuando também na Pós-graduação em Geografia, sendo membro da CoC - Comissão de Climatologia da UGI - União Geográfica Internacional (desde 2012) e do Conselho de Administração da AIC - Associação Internacional de Climatologia (2003-2006, e desde 2013). É pesquisador 1A-CNPQ desde 2013.

Centro Politécnico - Universidade Federal do Paraná - Av. Francisco H. dos Santos, $\mathrm{s} / \mathrm{n}$

Edifício João José Bigarella. Sala 210. CEP 81531-900, Curitiba - Paraná

E-mail: chico@ufpr.br
\end{abstract}

Recebido para publicação em janeiro de 2017

Aprovado para publicação em março de 2017 